ARTICLE

\title{
Exclusion diets and challenges in the diagnosis of food allergy
}

\author{
A C Lang, A I Manjra, A J Terblanche, S M Risenga, C L Gray, E Goddard, S Karabus, M Kriel, D A van der Spuy, M E Levin, \\ for the South African Food Allergy Working Group (SAFAWG)
}

All authors' degrees, affiliations and conflict of interest statements can be found online at http://dx.doi.org/10.7196/SAMJ.9201

Corresponding author: M Levin (michael.levin@uct.ac.za)

Instituting an exclusion diet for 2 - 6 weeks, and following it up with a planned and intentional re-introduction of the diet, is important for the diagnosis of a food allergy when a cause-and-effect relationship between ingestion of food and symptoms is unclear.

Food may be re-introduced after (short-term) exclusion diets for mild-to-moderate non-immunoglobulin E (IgE)-mediated conditions in a safe clinical environment or cautiously at home. However, patients who have had an IgE-mediated immediate reaction to food, a previous severe non-IgE-mediated reaction or a long period of food exclusion should not have a home challenge, but rather a formal incremental food challenge protocol in a controlled setting.

An incremental oral food challenge (OFC) test is the gold standard to diagnose clinical food allergy or demonstrate tolerance. It consists of gradual feeding of the suspected food under close observation. It should be done by trained practitioners in centres that have experience in performing the procedure in an appropriate setting.

An OFC must be performed in a setting where resuscitation equipment is available in the event of a severe anaphylactic reaction. OFCs are terminated when a reaction becomes apparent. Standardised and pre-set criteria are available on when to discontinue challenges. Patients who tolerate the full dose 'pass' the challenge and are advised to eat a full portion of the food at least twice a week to maintain tolerance. Those who have reactions have 'failed' the challenge, should avoid the food, receive education and implement risk-reduction strategies where appropriate. Patients should be observed for a minimum of 2 hours following a negative challenge and for 4 hours after a positive one.

S Afr Med J 2015;105(1):67-68. DOI:10.7196/SAMJ.9101

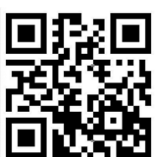

Exclusion diets become an important diagnostic tool when a cause-and-effect between ingestion of food and symptoms is unclear. This is most common when there is not an immediate reaction to the food. Diagnosis can usually be made by exclusion of the food for a specific period (usually 2 - 6 weeks), followed by planned and intentional re-introduction of the food.

\section{Types of diagnostic exclusion diets}

Single food exclusion, multiple food exclusion or few foods diets may be used as diagnostic tools. Occasionally, exclusive elemental diets and protein hydrolysate diets may be useful in diagnosing severe allergic disease. The type of exclusion diet will be determined by clinical history, social factors and other investigations.

\section{Duration of exclusion diets}

Food exclusion diets are usually followed for 2 - 4 weeks, but in some cases for up to 6 weeks. Most food exclusion diets should not be continued for longer than 3 - 4 weeks. ${ }^{[1]}$

\section{Considerations}

Food exclusion diets should take into consideration socioeconomic status, nutritional status and cultural/religious beliefs. Parents and children should be educated with regard to which foods and drinks to avoid, interpreting food labels and alternative sources of nutrition to ensure an adequate nutritional intake.

\section{Monitoring progress}

There are few nutritional risks in short-term diagnostic exclusion diets. However, extensive or long-term avoidance should be carefully monitored, as nutritional deficiencies may result. A symptom diary may be useful for a week before and during the diet. If there is no improvement, further restrictions or ruling out food allergy should be discussed. If possible, a registered dietician competent with regard to food allergy and paediatric patients should be consulted.

Food re-introduction after (short-term) exclusion diets for mild-to-moderate non-IgE-mediated conditions

Dietary exclusion needs to be followed up by food re-introduction in a safe clinical environment or cautiously at home. Patients who have had an IgE-mediated immediate reaction to food or a previous severe non-IgE-mediated reaction should not have home re-introduction, but be challenged with an incremental challenge protocol in a controlled setting. ${ }^{[2]}$ After prolonged exclusion ( $>6$ months) of a specific allergen from the diet, skin-prick tests (SPTs) or specific IgE (ImmunoCAP) tests to the specific allergen should be performed before re-introduction, as an IgE-mediated allergy may have developed.

To diagnose a non-IgE food allergy, foods should be re-introduced one at a time with sufficient time between re-introduction to ensure that a reaction has not occurred. Daily consumption for $3-4$ days is recommended before re-introduction of further allergens. Introduction of the food as a single ingredient rather than a composite food is preferred.

The order of re-introduction should be a clinical decision based on the likelihood of an allergic reaction (the least likely first), nutritional need for the allergen (nutritionally important allergens first) and condition being treated.

In food re-introduction diets, the quantity of food to be challenged should be discussed. Small incremental doses may be used for very small children or if reactions are likely to be severe. ${ }^{[2]}$ Ultimately, one 
Table 1. Food challenge doses for common food allergens ${ }^{*}$

\begin{tabular}{|c|c|c|c|c|c|c|c|c|c|}
\hline Food & $\begin{array}{l}\text { Dose 1, } \\
20 \text { min }\end{array}$ & $\begin{array}{l}\text { Dose 2, } \\
40 \mathrm{~min}\end{array}$ & $\begin{array}{l}\text { Dose } 3 \text {, } \\
60 \mathrm{~min}\end{array}$ & $\begin{array}{l}\text { Dose } 4, \\
80 \text { min }\end{array}$ & $\begin{array}{l}\text { Dose } 5, \\
100 \mathrm{~min}\end{array}$ & $\begin{array}{l}\text { Dose 6, } \\
120 \mathrm{~min}\end{array}$ & $\begin{array}{l}\text { Dose } 7, \\
140 \mathrm{~min}\end{array}$ & $\begin{array}{l}\text { Dose } 8, \\
160 \mathrm{~min}\end{array}$ & $\begin{array}{l}\text { Dose } 9, \\
180 \mathrm{~min}\end{array}$ \\
\hline Cow's milk & $0.1 \mathrm{~mL}$ & $0.5 \mathrm{~mL}$ & $1 \mathrm{~mL}$ & $5 \mathrm{~mL}$ & $10 \mathrm{~mL}$ & $20 \mathrm{~mL}$ & $40 \mathrm{~mL}$ & $100-200 \mathrm{~mL}$ & \\
\hline $\begin{array}{l}\text { Egg } \\
\text { (scrambled) }\end{array}$ & $10 \mathrm{mg}$ & $0.5 \mathrm{~g}$ & $1 \mathrm{~g}$ & $2 \mathrm{~g}$ & $5 \mathrm{~g}$ & $10 \mathrm{~g}$ & $20 \mathrm{~g}$ & $30-60 g$ & \\
\hline Soya milk & $0.1 \mathrm{~mL}$ & $0.5 \mathrm{~mL}$ & $1 \mathrm{~mL}$ & $5 \mathrm{~mL}$ & $10 \mathrm{~mL}$ & $20 \mathrm{~mL}$ & $40 \mathrm{~mL}$ & $100-200 \mathrm{~mL}$ & \\
\hline Hake (plain, poached) & $10 \mathrm{mg}$ & $0.5 \mathrm{~g}$ & $1 \mathrm{~g}$ & $2 \mathrm{~g}$ & $5 \mathrm{~g}$ & $10 \mathrm{~g}$ & $20 \mathrm{~g}$ & $30 \mathrm{~g}$ & $40-60 \mathrm{~g}$ \\
\hline $\begin{array}{l}\text { Wheat } \\
\text { (Weetbix) }\end{array}$ & $100 \mathrm{mg}$ & $1 \mathrm{~g}$ & $2 \mathrm{~g}$ & $5 \mathrm{~g}$ & $10 \mathrm{~g}$ & $20 \mathrm{~g}$ & $40-60 \mathrm{~g}$ & & \\
\hline $\begin{array}{l}\text { Wheat } \\
\text { (pasta) }\end{array}$ & $100 \mathrm{mg}$ & $1 \mathrm{~g}$ & $2 \mathrm{~g}$ & $5 \mathrm{~g}$ & $10 \mathrm{~g}$ & $20 \mathrm{~g}$ & $60-80 \mathrm{~g}$ & & \\
\hline Peanut butter & $10 \mathrm{mg}$ & $0.15 \mathrm{~g}$ & $0.3 \mathrm{~g}$ & $0.6 \mathrm{~g}$ & $1.2 \mathrm{~g}$ & $2.4 \mathrm{~g}$ & $5 \mathrm{~g}$ & $10 \mathrm{~g}$ & $15-30 \mathrm{~g}$ \\
\hline Roasted peanut & $10 \mathrm{mg}$ & $0.1 \mathrm{~g}$ & $0.25 \mathrm{~g}$ & $0.5 \mathrm{~g}$ & $1 \mathrm{~g}$ & $2 \mathrm{~g}$ & $4 \mathrm{~g}$ & $9 \mathrm{~g}$ & $13-25 g$ \\
\hline Tree nuts & $10 \mathrm{mg}$ & $0.1 \mathrm{~g}$ & $0.25 \mathrm{~g}$ & $0.5 \mathrm{~g}$ & $1 \mathrm{~g}$ & $2 \mathrm{~g}$ & $4 \mathrm{~g}$ & $9 \mathrm{~g}$ & $15-30 \mathrm{~g}$ \\
\hline
\end{tabular}

is working towards reintroducing an age-appropriate portion size similar to what was eaten before dietary exclusion.

\section{Food challenges}

An incremental oral food challenge (OFC) test consists of the gradual introduction of the suspected food under close observation. ${ }^{[3-6]}$ An OFC is preceded by a period of dietary exclusion. OFC testing is the gold standard to diagnose clinical food allergy or demonstrate tolerance. Food challenge is indicated where SPTs or specific IgE sensitisation does not clearly correlate with clinical symptoms. Incremental food challenge for IgE-mediated food allergy should be done by trained practitioners in centres where there is experience in performing the procedure in an appropriate setting.

\section{Reasons for OFC tests}

- To confirm the diagnosis of a specific food allergy.

- To determine if a food allergy persists or has resolved.

In situations where there is a clear reaction confirmed by significant levels of sensitisation on SPT or specific IgE testing, there is no need to perform an OFC.

\section{Caution}

OFCs performed after a period of exclusion may result in acute and severe reactions, even though the food was previously associated with chronic symptoms only. ${ }^{[4,7,8]}$ This occurs most commonly when there is a positive specific IgE test for the food.

\section{Types of food challenges ${ }^{[3,9,10]}$ Open OFC}

In an open OFC, the patient and doctor both know the content of the food. OFCs are a good option for screening when several foods are being considered, or there is minimal concern about observer or patient bias. In the case of an indeterminate challenge, it may need to be repeated with blinding and controls. Open challenges are also performed (at home) the day after a double-blind, placebo-controlled OFC to ensure that a mealsized portion of the food is tolerated in its natural state.

\section{Single-blind OFC}

In a single-blind OFC, the patient, but not the doctor, is blinded to the food. The food should be masked in taste by adding it to another food. This procedure helps to alleviate some patient bias. However, the single-blind OFC does not remove observer bias.

\section{Double-blind, placebo-controlled OFC}

In a double-blind, placebo-controlled OFC, neither the patient nor the doctor knows the content of the food. The food is concealed in another food and an equivalent-looking and -tasting placebo is used as a control challenge on another day. The order of the active compared with the placebo challenge is unknown to both doctor and patient. This is considered the gold standard for diagnosing food allergy and is preferred for research purposes. ${ }^{[3,11]}$

The procedure for double- and single-blinded challenges is more labour intensive than the open challenge, but can still be carried out in an office setting if the required materials and personnel are available. The aid of a third party is needed to prepare double-blind challenges.

\section{Performance of an OFC}

Consensus has not been reached on a uniform international protocol for performing OFCs. ${ }^{[11,12]}$ The protocol for an OFC (e.g. dosing, frequency) may need to be varied to match clinical issues (e.g. history of the reaction pattern). In all challenges, the food is given in gradually increasing amounts. Sample OFC protocols are given in Table 1.

\section{Patient preparation}

- Patient informed consent must be obtained and documented.

- Patients should avoid the suspected food(s) for at least 2 weeks before the OFC for possible IgE-mediated allergy, and for several more weeks for non-IgE-mediated reactions. 
- Patients should not eat or drink for at least 2 hours prior to challenge.

- Antihistamines, $\beta$-agonists, $\beta$-adrenergic blockers (including eye drops), and other medications that may either alter symptoms of a reaction or interfere with its treatment, should be discontinued for at least 5 half-lives of the specific drug prior to challenge.

- Patients should be instructed to bring their adrenaline auto-injector with them so that it is available on their way home after the test, should a delayed reaction occur.

- Patients are advised to cancel the OFC test if they are experiencing acute allergic symptoms or are otherwise ill at the time of their appointment.

- Patients with asthma should be symptom free and stable on current therapy, with no recent exacerbations. Spirometry may be performed to ensure a good baseline. Hospitalisation may infrequently be necessary to treat severe or acute allergic disease and establish a stable baseline prior to challenges.

\section{Location}

An OFC must be performed in a setting where resuscitation equipment is available in the event of a severe anaphylactic reaction. It may be performed in an outpatient or inpatient setting, depending on the patient's clinical history. In high-risk cases (previous severe reactions or severe asthma), one-onone nursing and insertion of an intravenous cannula may be required.

\section{Dosing and timing}

Many different protocols are available, but these should be modified to suit the patient's clinical circumstances. The final dose must represent an 'age-appropriate portion size' tailored to the child or individual.

Generally, one should select a regimen that is unlikely to result in a severe acute reaction by cautiously and gradually increasing the amount ingested (with the target cumulative dose of a meal-sized portion), while also considering time constraints.

For patients with previous food reactions immediately after ingestion, doses are generally administered at 15 - 20-minute intervals over about $140-180$ minutes, followed by a larger, meal-sized portion of food the next day.

\section{Monitoring}

Patients should be examined carefully prior to an OFC to determine their baseline and confirm that they do not have any significant allergic signs/symptoms or an illness that

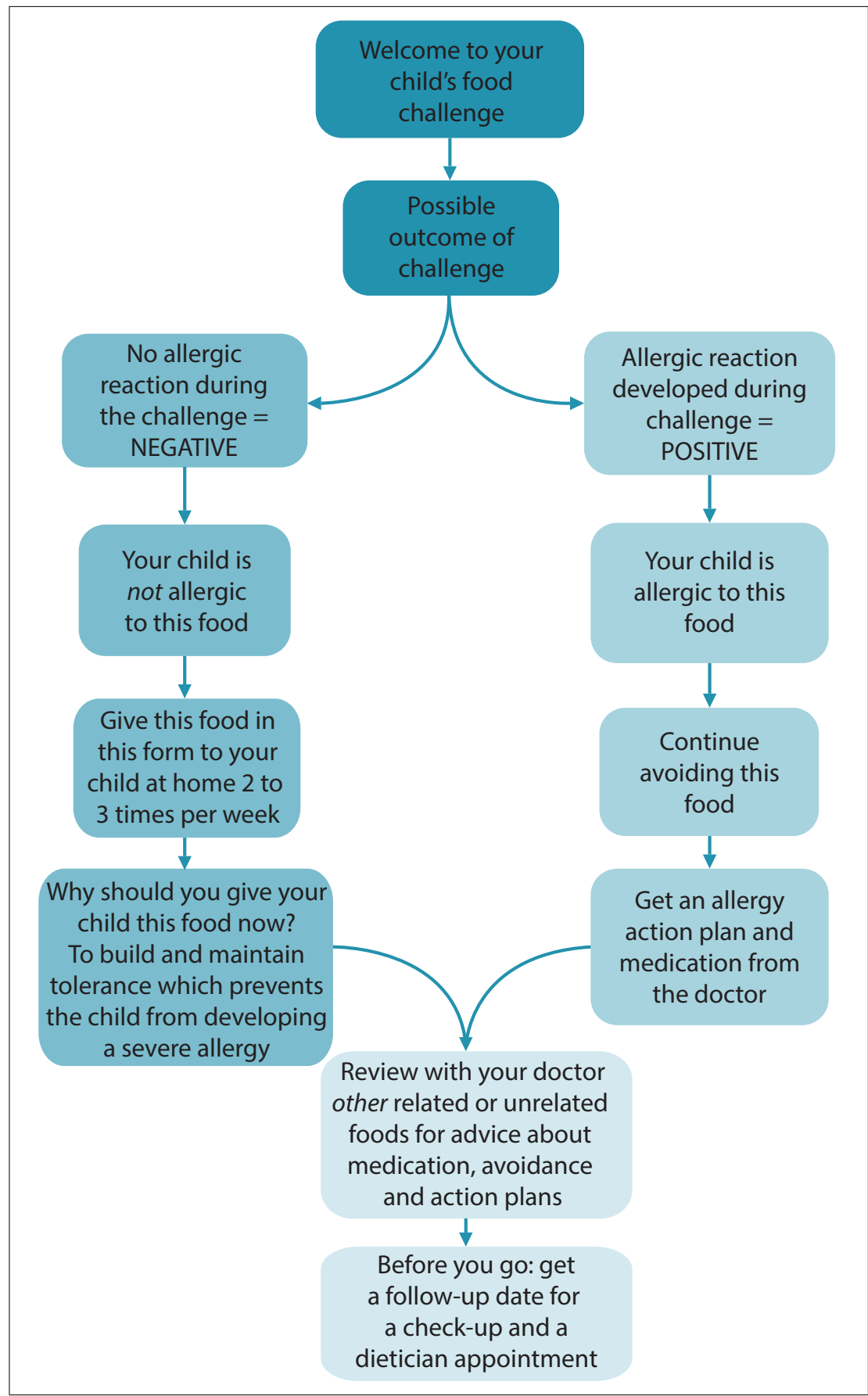

Fig. 1. Flowchart to facilitate patient education and ensure appropriate feedback and follow-up.

would interfere with assessment and/or treatment of a reaction during the challenge. Vital signs are measured and signs and symptoms are recorded at baseline, prior to each dose, and at set intervals after the final dose. Assessments are made for symptoms affecting the skin, cardiovascular system, and gastrointestinal and respiratory tracts. Scoring systems are useful in the research setting, but are not generally implemented in clinical practice. ${ }^{[3]}$

Children may suddenly become quiet or assume a fetal position prior to exhibiting more objective symptoms. Early indications of a reaction may include subtle signs, such as moving the tongue in the mouth to rub an itchy palate or ear pulling, as an indication of pruritus. Oropharyngeal pruritus or pain often precedes objective symptoms. ${ }^{[14,15]}$ Children with atopic dermatitis may display an eczematous flare.

\section{Discontinuing a challenge}

Challenges are terminated when a reaction becomes apparent. ${ }^{[5]}$ There are standardised and pre-set criteria available on when to discontinue challenges. ${ }^{[16]}$ The severity of a 
reaction does not necessarily correlate with the severity of reactions in real-life situations, as challenges are gradual and discontinued immediately if a reaction occurs. ${ }^{[17]}$

Following a negative OFC in which the allergen was administered in a form not normally eaten (e.g. peanut flour or powdered egg), it is essential to perform an OFC with a meal-sized portion of the food in the state in which it is normally ingested (e.g. peanut butter or boiled egg). This is done to ensure that the processing of the allergenic food for challenge did not alter the allergen and to confirm the negative result.

Patients should be observed for a minimum of 2 hours after a negative challenge and for 4 hours following a positive one.

\section{Interpreting the challenge}

Patients who tolerate the full dose 'pass' the challenge and are advised to eat a full portion of the food at least twice a week to maintain tolerance. Those who have reactions have 'failed' the challenge, should avoid the food, and receive education and risk-reduction strategies where appropriate. They may be guided by the study nurse, clinician or dietician. After the challenge, the patient should be seen by a clinician to review other unrelated food, and receive advice about avoidance, medication and action plans and dates for follow-up visits for medical and dietetic services (Fig. 1).

\section{References}

1. Kershaw R. Nutritional Consequences of Avoidance and Practical Approaches to Nutritional Management. In: Skypala I, Venter K, eds. Food Hypersensitivity. Diagnosing and Managing Food Allergy and Intolerances. Indianapolis: Wiley-Blackwell2009:241-264.
2. Niggemann B, Beyer K. Diagnosis of food allergy in children: Towards a standardization of food challenge- Pediatr Gastroenterol Nutr 2007;45:399-404 [http://dx.doi.org/10.1097/ MPG.0b013e318054b0c3]

3. Bock SA, Sampson HA, Atkins FM, et al. Double-blind, placebo-controlled food challenge (DBPCFC) as an office procedure: A manual. J Allergy Clin Immunol 1988; 82:986-987

4. American College of Allergy, Asthma \& Immunology. Food allergy: A practice parameter. Ann Allergy 4. American College of Allergy, Asthma \& Immu
Asthma Immunol 2006;96(3 Suppl 2):S1-S68.

Asthma Immunol 2006;96(3 Suppl 2):S1-S68.
5. Sicherer SH. Oral food challenges for diagnosis and management of food allergies. UpToDate, 2013. 5. Sicherer SH. Oral food challenges for diagnosis and management of food allergies. UpToDate, 2013.
http://www.uptodate.com/contents/oral-food-challenges-for-diagnosis-and-management-of-foodallergies (accessed 21 November 2014).

6. Fleischer DM, Bock SA, Spears GC, et al. Oral food challenges in children with a diagnosis of food allergy. J Pediatr 2011;158:578-583 [http://dx.doi.org/10.1016/j.jpeds.2010.09.027]

7. David TJ. Anaphylactic shock during exclusion diets for severe atopic eczema. Arch Dis Child 1984;59:983-986. [http://dx.doi.org/10.1136/adc.59.10.983]

8. Flinterman AE, Knulst AC, Meijer Y, et al. Acute allergic reactions in children with AEDS after prolonged cow's milk exclusion diets. Allergy 2006;61:370-374. [http://dx.doi.org/10.1111/j.13989995.2006.01018.x]

9. Sicherer SH. Food allergy: When and how to perform oral food challenges. Pediatr Allergy Immunol 1999;10:226-234. [http://dx.doi.org/10.1034/j.1399-3038.1999.00040.x]

10. Bindslev-Jensen C. Standardization of double-blind, placebo-controlled food challenges. Allergy 2001;56(Suppl 67):75-77. [http://dx.doi.org/10.1016/j.jaci.2012.10.017]

11. Sampson HA, Van Wijk GR, Bindslev-Jensen C, et al. Standardizing double-blind, placebo-controlled oral food challenges: American Academy of Allergy, Asthma \& Immunology-European Academy of Allergy and Clinical Immunology PRACTALL consensus report. J Allergy Clin Immunol 2012;130:1260-1274. [http://dx.doi.org/10.1016/j.jaci.2012.10.017]

12. Niggemann B, Wahn U, Sampson HA. Proposals for standardization of oral food challenge tests in infants and children. Pediatr Allergy Immunol 1994;5:11-13. [http://dx.doi.org/10.1111/j.1399-3038.1994.tb00212.x] 3. Lack G, Du Toit G, Feeney M. Oral food challenge procedures. In: James JM, Burks W, Eigenmann PA, eds. Food Allergy. Edinburgh: Elsevier, 2012:185-204.

14. Kok EE, Meijer Y, Kentie PA, et al. Oropharyngeal symptoms predict objective symptoms in doubleblind, placebo-controlled food challenges to cow's milk. Allergy 2009;64:1226-1227. [http://dx.doi. org/10.1111/j.1398-9995.2009.02000.x]

15. Flinterman AE, Hoekstra MO, Meijer $\mathrm{Y}$, et al. Clinical reactivity to hazelnut in children: Association with sensitization to birch pollen or nuts? J Allergy Clin Immunol 2006;118:1186-1189. [http://dx.doi. org/10.1016/j.jaci.2006.08.017]

16. Koplin JJ, Tang ML, Martin PE, et al. Predetermined challenge eligibility and cessation criteria for Koplin JJ, Tang ML, Martin PE, et al. Predetermined challenge eligibility and cessation criteria for
oral food challenges in the HealthNuts population-based study of infants. I Allergy Clin Immunol 2012;129(4):1145-1147. [http://dx.doi.org/10.1016/jijaci.2011.09.044]

17. Hourihane JO, Grimshaw KE, Lewis SA, et al. Does severity of low-dose, double-blind, placebocontrolled food challenges reflect severity of allergic reactions to peanut in the community? Clin Exp Allergy 2005;35:1227-1233 [ http://dx.doi.org/10.1111/j.1365-2222.2005.02312.x ] 